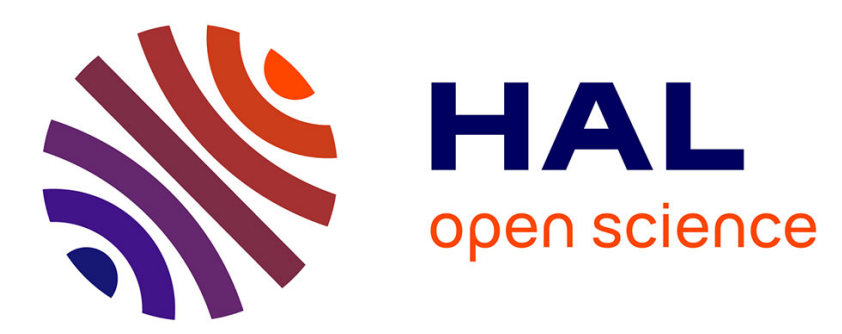

\title{
The microstructure of plasma arc cold-hearth melted $\mathrm{Ti}-48 \mathrm{Al}-2 \mathrm{Mn}-2 \mathrm{Nb}$
}

\author{
Thomas Johnson, N. Jesper, J. Young, R. Ward, M. Jacobs
}

\section{To cite this version:}

Thomas Johnson, N. Jesper, J. Young, R. Ward, M. Jacobs. The microstructure of plasma arc cold-hearth melted Ti-48Al-2Mn-2Nb. Journal de Physique IV Proceedings, 1993, 03 (C7), pp.C7371-C7-376. 10.1051/jp4:1993758 . jpa-00252177

\section{HAL Id: jpa-00252177 https://hal.science/jpa-00252177}

Submitted on 1 Jan 1993

HAL is a multi-disciplinary open access archive for the deposit and dissemination of scientific research documents, whether they are published or not. The documents may come from teaching and research institutions in France or abroad, or from public or private research centers.
L'archive ouverte pluridisciplinaire HAL, est destinée au dépôt et à la diffusion de documents scientifiques de niveau recherche, publiés ou non, émanant des établissements d'enseignement et de recherche français ou étrangers, des laboratoires publics ou privés. 


\title{
The microstructure of plasma arc cold-hearth melted Ti-48Al-2Mn-2Nb
}

\author{
T.P. JOHNSON, N.E. JESPER, J.M. YOUNG, R.M. WARD and M.H. JACOBS
}

The Interdisciplinary Research Centre in Materials for High Performance Applications, The University of
Birmingham, Elmis Road, Edgabaston, B15 2TT, United Kingdom

\begin{abstract}
The purpose of this paper is to show the results of some work at the IRC in Materials for High Performance Applications at the University of Birmingham into the effect of processing and process parameters on the microstructure, macrostructure and chemistry of $100 \mathrm{~mm}$ diameter single plasma-melted ingots of a gamma-based titanium aluminide (Ti-48at\% Al-2at $\% \mathrm{Mn}-2 \mathrm{at} \% \mathrm{Nb})$. The microstructure of the asmelted bars is almost completely lamellar and consists of a chill layer of fine prior alpha grains at the surface and larger columnar grains growing into the centre of the bar. These microstructural features show little variation with processing conditions. The orientations of the alpha grains have been used to determine the effect of plasma torch current and ingot withdrawal rate on melt pool shape under a variety of operating conditions and it has been established that, at typical operating conditions, the ingot withdrawal rate has a more significant effect on melt pool depth than the plasma torch current, especially at faster withdrawal rates. Chemical analyses has shown that there is negligible net loss of any of the major alloying elements, although the degree of as-cast chemical homogeneity needs to be increased in the light of the extreme microstructural sensitivity. Further investigation has shown that one major cause of inhomogeneity is macrosegregation induced by short-term variations in melt pool shape. The implications of these results for the processing of titanium aluminides are then discussed.
\end{abstract}

\section{INTRODUCTION}

The Interdisciplinary Research Centre in Materials for High Performance Applications (IRC in Materials) was established in 1989 at the Universities of Birmingham and Swansea; one of the main aims being the development of new materials for high performance applications through the parallel development of novel processing techniques. As part of the portfolio of programmes, a systematic study is being made of the primary processing and resultant structures and properties of the family of intermetallics based on titanium and aluminium, principally gamma-based titanium aluminides (TiAl and its derivatives).

The intermetallics primary processing programme at the IRC in Materials falls into three categories:

0 plasma arc cold-hearth melting, to produce clean melted ingots

gas atomisation, using remelted clean-melted feedstock, to produce clean powder

spray forming, again using clean-melted feedstock, to form sheet and ring products.

The main emphasis to date has been on ingot melting, but small quantities of powder and spray formed preforms have been produced and evaluated (1-3).

Plasma arc melting is a cold-hearth refining process and as such the metal is melted into a water-cooled copper hearth to form a solid 'skull', which then acts as a secondary hearth of the same composition as the parent metal. This prevents the pick up of melt-related inclusions by excluding harmful refractories from the melting process and allows time for existing inclusions to either sink into the skull or dissolve into the melt before flowing into a water-cooled copper crucible to solidify and for this reason, these processes are also known as 'clean melting' processes. Cold-hearth melting is seen as an alternative to other melting techniques such as vacuum arc remelting (VAR) and electroslag refining (ESR) for reactive metals where metal cleanness is regarded as being of great importance $(4,5)$. Two types of heat source are suitable for this type of melting; electron beam and plasma-arc heating. The different characteristics of the two heat sources mean that they have slightly different applications. In particular, the high vacuum and consequent loss of volatile elements, such as aluminium, in electron beam melting mean that plasma arc melting is the more suitable for the production of titanium aluminides.

Results of detailed microstructural examination of Ti-48at\%Al-2at\%Nb-2at\%Mn ingots produced at the IRC in Materials during the period February - November 1991 have been reported elsewhere $(6,7)$. Forging of this early material and Ti48at\%Al has also been investigated within the IRC by Zhang et al (8) and the heat treatment of forged billets has been reported by Zhang et al (9). 
The aim during the second ingot programme ( September 1992 -June 1993 ) has been to obtain a more detailed understanding of the effects of process variables on the ingot melt pool shape and ingot quality. The processing parameters investigated include crucible torch power, ingot withdrawal rate, dither (the ability to reciprocate the ingot within the crucible during casting) and electromagnetic stirring. Understanding the relationships between processing and ingot quality is of great importance for a number of reasons. Firstly, it enables us to know what aspects of the process are most critical in determining the microstructures, macrostnuctures and chemistries of the as-melted ingots; knowledge which is essential in order to establish processing windows and in the overall control of the process. Secondly, it reveals the extent of the variations in microstructure that can be achieved through controlled variations in the processing conditions. Thirdly, it provides valuable information for the validation of mathematical thermal models of the process. The aspects of bar quality that will be considered in this paper are the microstructural features present, the macrostructural distributions and orientations of those features and the chemical composition and homogeneity of single melted Ti-48at\%Al-2at\%Mn-2at\% Nb (hereafter referred to as Ti-48-2-2). The processing parameters considered in this paper are the rate at which the material is cast into and withdrawn from the crucible, and the current drawn by the crucible torch, i.e. the torch used to hot top the ingot in the crucible.

\section{PLASMA MELTING FURNACE}

The furnace, a schematic of which is shown in Fig. 1 , is capable of producing ingots of $100 \mathrm{~mm}$ and $150 \mathrm{~mm}$ diameter, and up to $1.4 \mathrm{~m}$ in length. It is powered by two $150 \mathrm{~kW}$ servo-hydraulic, computer-controlled transfer arc plasma torches which use helium as the plasma gas. One torch melts feedstock into a water-cooled copper hearth to form the skull. Liquid metal then flows through a pouring notch from the hearth into a water-cooled copper crucible with a retractable base to form a continuous ingot. A computerised data acquisition system is used to monitor and record operating conditions such as torch power, water temperature, gas pressure, as well as the furnace exhaust gases. Before melting commences, the furmace is evacuated to a pressure of $<40 \mu$ bar. Provided the leak up rate is $<3 \mu \mathrm{bar} / \mathrm{min}$, the furnace is then back filled with argon to a pressure of 1.1 bar, which is maintained throughout the melting process.

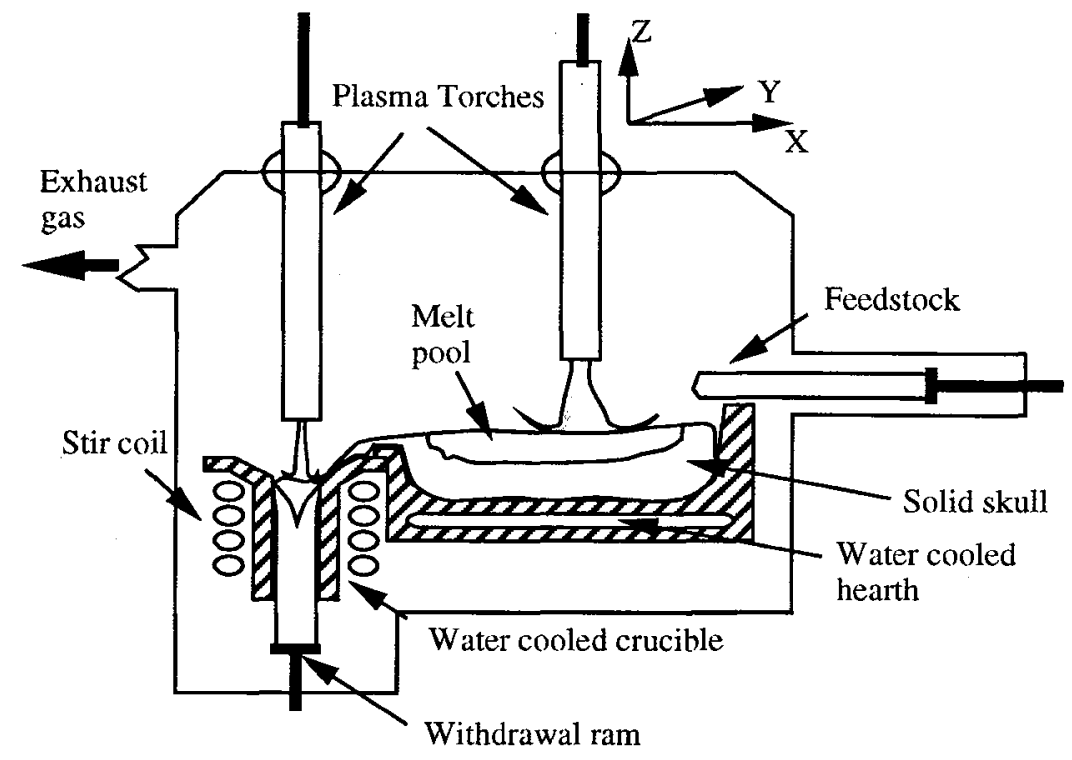

Fig 1. Schematic diagram showing plasma cold-hearth melting facility.

\section{EXPERIMENTAL PROCEDURE}

Several $1.4 \mathrm{~m}$ by $100 \mathrm{~mm}$ diameter bars of Ti-48-2-2 were produced by single melting elemental compacted feedstock supplied by IMI Titanium Ltd. A number of different crucible torch powers and withdrawal rates were used which, taken together, cover the complete range of normal operating conditions for these two parameters. The exact conditions used in each section were established from the detailed data acquisition records of the runs and longitudinal sections cut at selected points. Longitudinal metallographic sections of the bars were taken along the diameter which was parallel to the long axis of the hearth, i.e. in the plane of the diagram shown in Fig 1 . These were then ground and lapped before being macroetched to reveal the prior alpha grain structure. Chemical analysis results have been obtained by glow discharge analysis, based on standards previously analysed by IMI Titanium Ltd., and each analysis result represents the mean of three results from the point of interest each of which was taken over a $4 \mathrm{~mm}$ diameter area. 


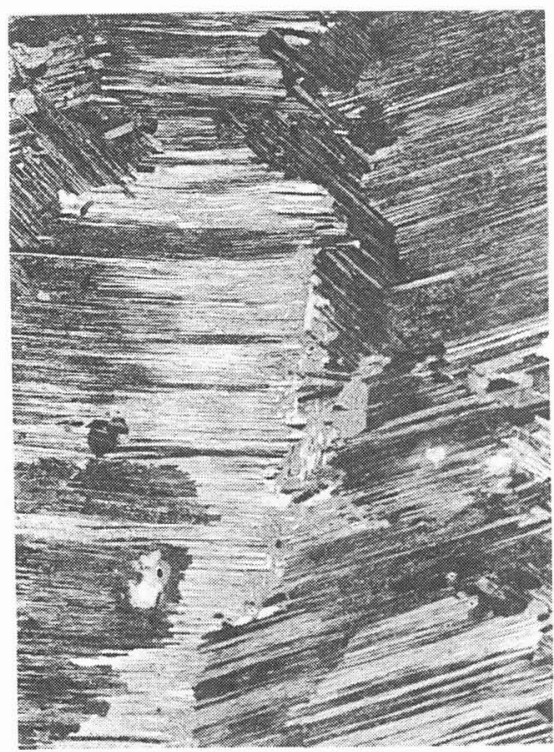

$0.2 \mathrm{~mm}$

Fig 2. Optical micrograph showing randomly orientated, equiaxed chill grains at the edge of plasma melted bar of Ti$48 \mathrm{Al}-2 \mathrm{Mn}-2 \mathrm{Nb}$.

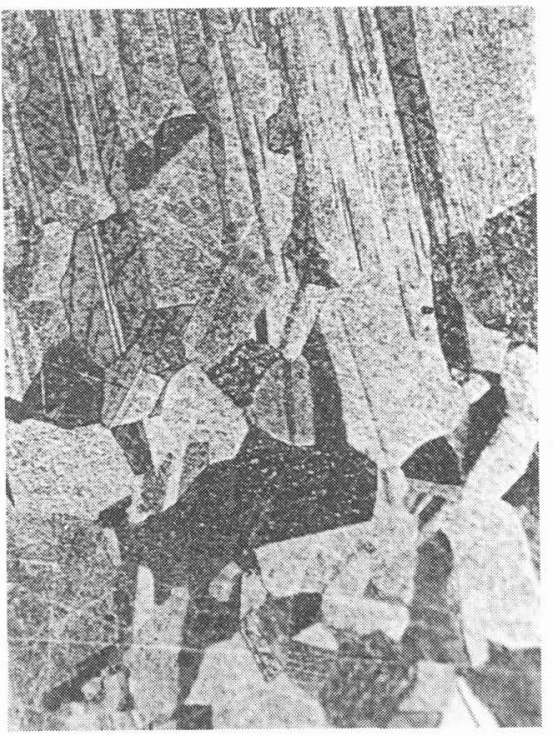

$50 \mu \mathrm{m}$

Fig 3. Optical micrograph showing alpha plus gamma lamellae within prior alpha grains in a plasma melted bar of $\mathrm{Ti}-48 \mathrm{Al}-2 \mathrm{Mn}-2 \mathrm{Nb}$.

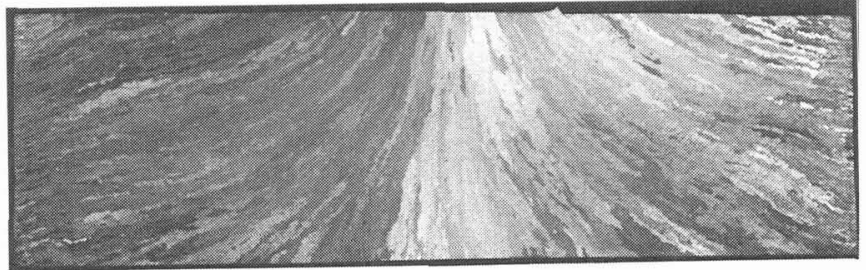

Fig 4. Optical micrograph showing transverse macrostructure of plasma melted $\mathrm{Ti}-48 \mathrm{Al}-2 \mathrm{Mn}-2 \mathrm{Nb}$ cast at a withdrawal rate of $12.7 \mathrm{~mm} / \mathrm{min}$ and at a torch power of $400 \mathrm{~A}$.

\section{RESULTS AND DISCUSSION OF RESULTS MICROSTRUCTURAL FEATURES}

The microstructures of the as-cast ingots show two distinct regions. The edge of the bar is characterised by a chill layer up to $2 \mathrm{~mm}$ thick consisting of randomly orientated, equiaxed, prior alpha grains each of which contain alpha- 2 plus gamma lamellae, as shown in Fig 2. This region of the bar contains occasional shrinkage pores up to $1 \mathrm{~mm}$ in diameter. In addition to these pores, some small areas have been observed and initial investigations indicate these are associated with areas of manganese segregation. The origin and nature of these areas are the subject of further investigation at the time of publication. The bulk of the section of the bar is characterised by fully lamellar prior alpha columnar grains with widths of around 0.4 to $0.6 \mathrm{~mm}$, as shown in Fig 3. These are highly orientated and grow upwards and into the centre of the bar, counter to the direction of maximum heat extraction. A region of indistinct microstructure forms at many of the prior alpha grain boundaries. The bulk of the as-cast bar is also characterised by heavy coring of the prior alpha dendrites. A typical longitudinal macrostructure of the as-cast ingot is shown in Fig 4. These basic microstructural features are common to all the conditions used for this paper.

\section{MELT POOL DEPTHS}

The macrostructures of the transversé sections have been used to determine the melt pool depths. This has been done by measuring the orientation of the columnar, prior alpha grains at each point across a longitudinal section and then constructing a curve mathematically which lies perpendicular to the alpha grains across the width of the ingot. This approach was felt to be the most accurate method of establishing melt pool shape since the characteristic 'tide marks' which are often used to locate melt pools in other continuously cast materials are quite faint in all the Ti-48-2-2 sections. It should be noted that where the tide marks could be seen there was very close agreement between them and the constructed curves. In the sections examined there are often small differences between the shape of the melt pool in the portion of the bar closest to the hearth (hereafter referred to as the front of the bar) as compared with that in the portion furthest from the hearth (i.e. the back of the bar). To eliminate the effect of these differences to obtain a 'mean' pool shape for each condition the orientations of the alpha grains at equivalent points on opposite sides of the bar were averaged and the melt pool shape constructed from the resulting orientations. A typical melt pool constructed in this way is shown in Fig 5 and the variation in the depth of the melt pool is shown for two torch currents and two withdrawal rates in Fig 6. 


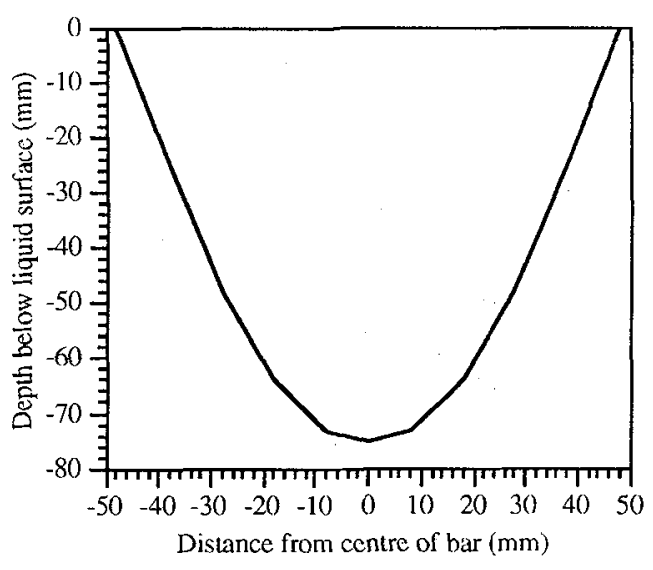

Fig 5. Typical inferred melt pool in a $100 \mathrm{~mm}$ diameter ingot, taken from a section melted at a torch current of 550 $A$ and at a withdrawal rate of $27^{\prime \prime}$ per hour.

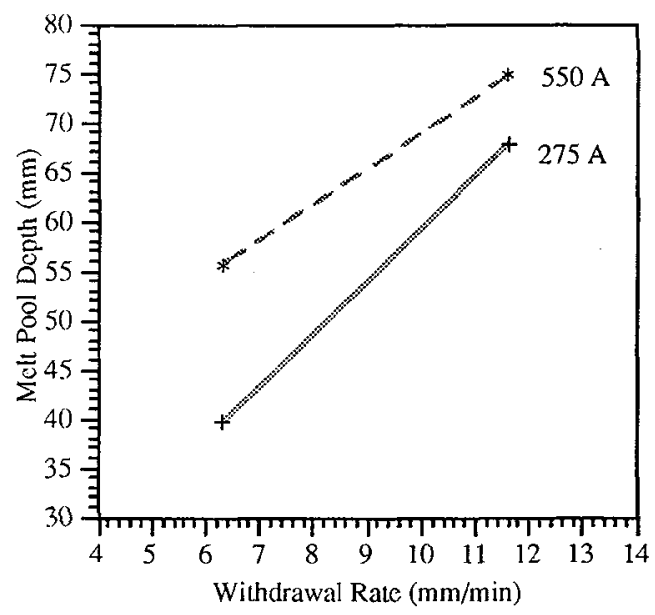

Fig 6. Graph of the effect of variations in withdrawal rate on melt pool depth for two different torch currents (550 and 275 A).

Fig 6 shows that at the faster withdrawal rate the elfect of plasma torch current on melt pool depth is quite small when compared with the eflect of changes in the withdrawal rate. At slower withdrawal rates, however, the sensitivity of melt pool depth to torch current is increased, possibly becausc of the decreased contribution to the heat input from the fresh metal entering the crucible from the hearth when compared to the faster withdrawal rate.

\section{CHEMICAL HOMOGENEITY}

Gamma-based titanium aluminides are extremely sensitive to chemical composition with regard to the response of the microstructure to subsequent heat treatment. Therefore a high degrec of compositional control is essential. Fig 7 shows all the aluminium, manganese and niobium analysis results of the single meited Ti-48Al-2-Nb-2Mn bars produced in the plasma melting facility from elemental compacts during the current round of melting, taken from a number of locations along each bar and from several points at cach location. It should be emphasised that these results were generated from a very wide range of processing conditions and therefore the distributions shown are a 'worst case' with respect to maintaining constant operating conditions. The purpose of the graphs is to show that in cach case there is a negligible difference between the mean analysed compositions and the blend compositions, which serves to illustrate that melting under a slight positive pressure of argon reduces preferential evaporation of volatile clements such as $\mathrm{Al}$ and $\mathrm{Mn}$ to very low levels. The spread of $\mathrm{Al}$ contents shown in the figure is appreciable, given the great sensitivity ol aluminide microstructures to chemical composition but, clearly since there is no net loss of any of the alloying elements, any deviations in composition from the blend composition must be associated with segregation of some sort. To investigate this further longitudinal sections were taken through a $200 \mathrm{~mm}$ section of an ingot at a point where the casting was intcrupted for a period of approximately 8 minutes. Chemical analysis was performed at $10 \mathrm{~mm}$ intervals down the centre line of the bar and $20 \mathrm{~mm}$ from the front surface of the bar and measurements of the alpha grain orientation were taken over the whole areat of the section. Mclt pool shapes were calculated at regular intervals and these were compared with the analysis results in order to examine the effect of changes in the melt pool shape on solute segregation.

Fig 8 shows the variation in Al content at central and mid radial points along the section of the bar and the variation in melt pool depth, measured by taking the depth $5 \mathrm{~mm}$ from the cdge of the bar as a datum, plotted as a function of the position of the centre of the melt pool. Note that in order to compare the deviations of the central and mid radial analyses at the same moment in time the mid radial analyses points have been plotted as a function of the position of centre of the melt pool on which they lie, i.e. analyses which lie on the same isotherm are plotted with the same position value. Note also that each analysis result corresponds to the results taken from a single $4 \mathrm{~mm}$ diameter area. Figure 8 shows that the pause in the casting rate leads to a reduction in the melt pool depth and that this is accompanied by considerable solute segregation, with a rise in Al content of around $1 \mathrm{wt} \%$ at the mid radial point at the expense of a similar fall in Al content in the centre. The degree of segregation in this region is comparable to the spread of analyses observed in Fig 7; this spread may well be due to segregation duc to varying melt-pool depth, especially given the wide range of conditions represented by those analyses. The same pattem of segregation is repeated with $\mathrm{Mn}$ and $\mathrm{Nb}$. However, it should also be noted that the spread in Al contents at other points on the section slightly away from the change in melt pool shape is approximately $0.6 w \%$. Further work is underway to investigate this phenomenon in more detail, but this would $5 \mathrm{ecm}$ to be a case of straightlorward dendritic or 'inverse' segregation. This form of segregation occurs in castings as the dendrites grow and reject solute rich liquid, which is then drawn down to the roots of the dendrite mesh by the shrinkage of the dendrites due to solidification. This leads to the formation of a solute-rich area towards the cooler areas of the ingot and a Ti-rich area in the centre. The steep temperature gradients and slow cooling rates in the crucible provide ideal conditions for this kind of segregation to occur and, although during smooth 
operation an equilibrium state is quickly reached and maintained, it is quite plausible that a change of the melt pool shape could disturb this equilibrium and lead to segregation.

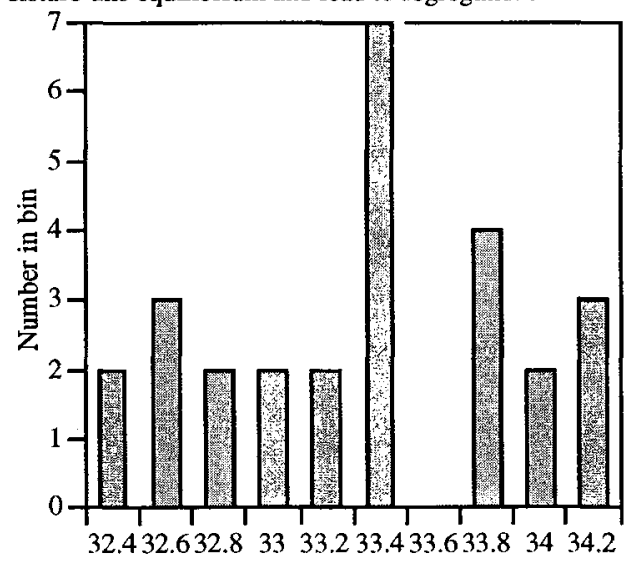

Al concentration (wt \%)
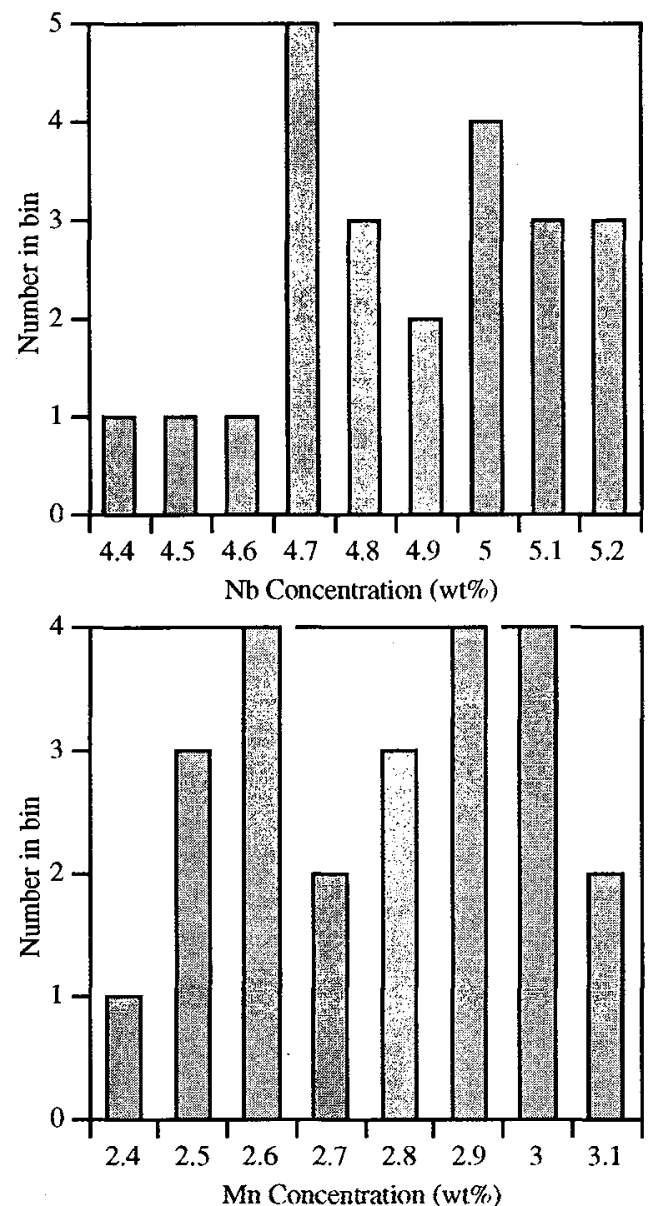

Fig 7. Graphs showing distributions of $\mathrm{Al}, \mathrm{Nb}$ and $\mathrm{Mn}$ concentrations in single plasma melted Ti-48Al-2Nb-2Mn (Ti-33.3wt\%Al-4.9wt\% Nb-2.8wt\% Mn)

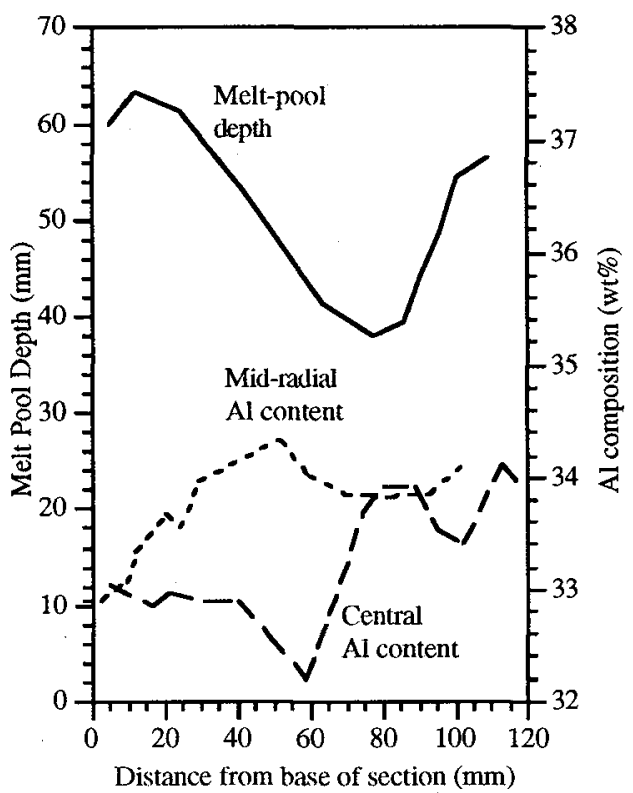

Fig 8. Graph showing Al compositions at central and midradial points and melt pool depth as a function of position along a single melted bar.

\section{IMPLICATIONS OF RESULTS}

The spread of compositions shown in Fig 7 and the occurrence of dendritic segregation as a result of a pause in the melting process illustrates the importance of mainlaining constant melting conditions in order to maintain close compositional control. Further work is needed to investigate other causes of ingot compositional inhomogeneity, such as variations in feedstock compositional homogeneity and variations in melt pool shape in the hearth, and to establish the sensitivity of the segregation to changes in processing conditions. Once this is better understood, results such as those presented in Fig 6 and other similar work will lead to the definition of processing windows and practices which will allow improved levels of control over the chemical homogeneity of the cast material. For example, it is hoped that this will provide information on such questions as whether changes in plasma torch power can be used to compensate for variations in withdrawal rate in order to minimise segregation in this way.

Another important implication of the segregation shown in Fig 8 is that the degree of inhomogeneity that will be detected by chemical analysis will depend quite sensitively on the size of the area over which chemical analysis is taken. The central and mid radial analysis profiles are approximately $28 \mathrm{~mm}$ apart. Therefore, if analysis had been carried out over an area $40 \mathrm{~mm}$ in diameter on this section a smaller deviation would been detected and it is possible that little deviation from the mean composition would have been detected at all. 


\section{CONCLUSIONS}

1. The microstructure of the as-melted bars is almost completely lamellar and consists of a chill layer of fine prior alpha grains at the surface and larger columnar grains growing into the centre of the bar. These microstrucutrural features show little variation with processing conditions.

2. At typical operating conditions, the ingot withdrawal rate has a more significant effect on melt pool depth than the plasma torch current, especially at faster withdrawal rates.

3. Single plasma arc melting at a pressure a little above atmospheric pressure leads to negligible net loss of any of the major alloying elements.

4. One major cause of chemical inhomogeneity in the as-cast ingots is dendritic segregation induced by short-term variations in melt pool shape.

\section{ACKNOWLEDGEMENTS}

The authors would like to acknowledge the help and support of Professor M.H. Loretto and also financial support of the U.K. Science and Engineering Research Council. They are also indebted to the considerable efforts and technical support of the whole of the plasma melting team.

\section{REFERENCES}

1. M.H. Jacobs, et al. "Production, Processing and Characterisation of Plasma Clean Melted Gas-Atomised Titanium Powders". (Paper presented at the Intemational Conference on Aerospace Defence and Demanding Applications, San Diego, USA, February 8-10, 1993, Metal Powders Industries Federation), in press.

2. T P Johnson, et al. "Gas Assisted Spray Deposition of Clean Melted Ti-48Al and Ti-48Al-2Mg-2Nb". (Paper presented at the International Conference on Aerospace Defence and Demanding Applications, San Diego, USA, February 8-10, 1993, Metal Powders Industries Federation), in press.

3. J M Young, et al. "Centrifugal Spray Deposition of Titanium Aluminides". (Paper presented at the International Conference on Aerospace Defence and Demanding Applications, San Diego, USA, February 8-10, 1993, Metal Powders Industries Federation), in press.

4. M J Blackburn and D R Malley. "Plasma Arc Melting of Titanium Alloys". (Paper presented at IRC"92 - Processing, Properties and Applications of Metallic and Ceramic Materials, Eds. M H Loretto and C J Beevers, MCE Publications Ltd., September 1992,) Vol.1, 99-118.

5. R Bakish. "Electron Beam Processing" Advanced Materials and Processes, ASM International, 142 (1992), No.6, 25.

6. J W Sears, J M Young and M W Keams. "The Effects of Plasma Cold Hearth Melting on the Production of Titanium Alloy Ingots". (Paper presented at the 7th World Conference on Titanium, San Diego, USA, June 28-July 2nd 1992, Eds. F $H$ Froes and I L Caplan) in press.

7. R V Ramanujan et aI; "The Chemistry and Structure of Plasma Melted Gamma-Based Titanium Aluminide". (Paper presented at the 7th World Conference on Titanium, San Diego, USA, June 28-July 2nd 1992, Eds. F H Froes and I L Caplan) in press.

8. X D Zhang, et al. "The Intluence of Forging on the Microstructure of Plasma Melted Gamma-Based Titanium Aluminides. (Paper presented at the 7th World Conference on Titanium, San Diego, USA, June 28-July 2nd 1992, Eds. F H Froes and I L Caplan) in press.

9. X D Zhang, et al. "The Influence of Heat Treatment on the Macrostructure of Gamma-Based Ti-Al Alloys". (Paper presented at IRC'92 - Processing, Properties and Applications of Metallic and Ceramic Materials, Eds. M H Loretto and C J Beevers, MCE Publications Ltd., September 1992, ) Vol.2, 637-642. 